\title{
Detection of a New and Unusual Isolate of Plum pox virus in Plum (Prunus domestica)
}

\author{
D. James, A. Varga, D. Thompson, and S. Hayes, Centre for Plant Health, Canadian Food Inspection Agency, \\ Sidney, British Columbia, V8L 1H3, Canada
}

\begin{abstract}
James, D., Varga, A., Thompson, D., and Hayes, S. 2003. Detection of a new and unusual isolate of Plum pox virus in plum (Prunus domestica). Plant Dis. 87:1119-1124.

Plum pox virus (PPV) isolate 3174-01 was detected by triple-antibody sandwich enzyme-linked immunosorbent assay using the universal PPV monoclonal antibody (MAb) 5B as the secondary antibody, and by reverse-transcription polymerase chain reaction (RT-PCR) using primers that amplify a 243-bp fragment in the C-terminus of the coat protein coding region. The restriction sites $R s a \mathrm{I}$ and $A l u \mathrm{I}$ were absent from this fragment, which is a feature unique to PPV-C isolates. The restriction sites in 3174-01 were replaced by GTAA/GTGA and GGCA, respectively. There was 95 to $99,94,91$, and 92 to $94 \%$ identity of the 243-bp fragment of 3174-01 with the corresponding region of the strains $\mathrm{C}, \mathrm{D}, \mathrm{EA}$, and $\mathrm{M}$, respectively. Attempts to detect the virus by RT-PCR using strain C-specific primers in three different approaches were unsuccessful. All molecular techniques assessed in attempting to strain type isolate 3174-01 gave negative results, or results inconsistent for $\mathrm{D}$ or $\mathrm{M}$ in the case of $\mathrm{P} 3-6 \mathrm{~K}_{1}$ restriction fragment length polymorphism analysis. Isolate 3174-01 reacted in Western blot assay with MAb 5B, with an estimated molecular mass of $32 \mathrm{kDa}$. No reaction was observed with D-, M-, EA-, or C-specific monoclonal antibodies in Western blot or enzyme-linked immunosorbent assay. The molecular and serological data seem to indicate that PPV isolate 3174-01 does not belong to any of the recognized strains of PPV.
\end{abstract}

Plum pox virus (PPV) causes plum pox or Sharka disease, which is considered the most devastating disease of stone fruits. Stone fruits infected by PPV include plum, peach, apricot, nectarine, sweet cherry, and sour cherry $(5,14,16,17)$. The genome of PPV consists of approximately $10 \mathrm{~kb}$ (13) with a virus-encoded protein covalently linked to the $5^{\prime}$ terminus of the genome, and a poly(A) tail at the $3^{\prime}$ end. The complete nucleotide sequences of several PPV isolates have been determined $(11,13,21)$. This has facilitated detailed analysis, comparison, and specific detection of the virus.

There are four recognized strains of PPV (D, M, EA, and C), which differ in pathogenicity, host range, efficiency of aphid transmission, and geographic distribution $(3,15,18,20)$. Consequently, strain identification is important in the management or successful eradication of this disease. There are serological and molecular techniques that allow reliable identification and differentiation of PPV strains. Each strain appears to have unique epitopes that

Corresponding author: D. James

E-mail: jamesd@inspection.gc.ca

Accepted for publication 21 April 2003.

Publication no. D-2003-0623-04R

This article is in the public domain and not copyrightable. It may be freely reprinted with customary crediting of the source. The American Phytopathological Society, 2003. have facilitated the development of monoclonal antibodies specific to strain D (2), M (1), C, and EA (14). Nucleic acidbased approaches to strain identification include: reverse-transcription polymerase chain reaction (RT-PCR) with strainspecific primers (15), RT-PCR with restriction fragment length polymorphism (RFLP) analysis $(7,8,23)$, Heminested PCR with D- and M-specific primers (18), PCRenzyme-linked immunosorbent assay (ELISA) $(18,19)$, and integrated RT-PCR/ nested PCR (20).

PPV recently was detected in the United States (12), and Canada (22). Attempts to eliminate the virus are ongoing and to determine the extent of spread and distribution of the virus. Strain typing is carried out when the virus is detected in a new location in Canada. This article describes attempts at strain typing an isolate of PPV detected in plum trees found growing on the property of a homeowner in the province of Ontario.

\section{MATERIALS AND METHODS}

Virus isolates. The virus isolate 317401 is a Canadian isolate of PPV detected in plum (Prunus domestica) in the garden of a residential property owner during the course of a PPV survey of Prunus spp. on homeowner properties in the Stoney Creek area, Ontario. The virus was mechanically sap-transmitted to Nicotiana benthamiana by triturating infected plum leaves in 0.01 delimitation surveys are being conducted
M potassium phosphate buffer containing $0.02 \mathrm{M}$ diethyldithiocarbamic acid (sodium salt), $0.04 \mathrm{M}$ sodium thioglycolate, and $0.5 \%$ nicotine. Several known or wellcharacterized isolates of PPV were included in this study as positive controls. Isolates PPV-Fa (20-4-1) and PPV-Vu (2013-1) are Canadian isolates of PPV detected in symptomless nectarine (cv. Fantasia) and in symptomatic clingstone peach (cv. Vulcan), respectively. These two isolates have been identified as D type $(9,22)$. The isolate Q1902-01 (PPV Marcus, type member $M$ strain) was obtained from F. Dosba, France; isolate Q2185-02, D type, was obtained from W. Jelkmann, Germany; PPV-C (a sweet cherry isolate) and PPV-EA (El Amar) were obtained as freeze-dried tissue samples from A. Myrta, Italy.

Triple antibody sandwich ELISA. Triple-antibody sandwich (TAS)-ELISA was carried out as described by Clark and Adams (4). The secondary antibody included the following PPV-derived monoclonal antibodies (MAbs): (i) 5B (a universal PPV MAb obtained from the REAL Durviz TAS ELISA kit), (ii) 4D (D-specific MAb obtained from M. Cambra, Valencia, Spain), (iii) AL (M-specific MAb), (iv) EA24 (El Amar-specific MAb), and (v) AC (C-specific MAb). All MAbs were used at a 1:1000 dilution. The antibodies MAbAL, MAb-EA24, and MAb-AC were kindly provided by A. Myrta, Bari, Italy. The instructions in the Durviz kit were followed except for (i) use of a modified grinding buffer (phosphate-buffered saline [PBS]-Tween, $0.2 \%$ skim milk powder, and $2 \%$ polyvinylpyrrolidone [PVP]) and (ii) inclusion of a blocking step using PBSTween with $0.2 \%$ skim milk powder for 30 min at room temperature. Approximately $0.5 \mathrm{~g}$ of leaf tissue was triturated in the grinding buffer using a 1:10 ratio (wt/vol). The homogenate was added to microtiter plates $(200 \mu \mathrm{l} /$ well $)$ that then were stored overnight at $4^{\circ} \mathrm{C}$. The monoclonal antibody and conjugate were used at a 1:000 dilution and stored at $37^{\circ} \mathrm{C}$ for $3 \mathrm{~h}$ and $4^{\circ} \mathrm{C}$ for 16 $\mathrm{h}$, respectively. The substrate nitrophenyl phosphate was used at $0.6 \mathrm{mg} / \mathrm{ml}$. Samples with absorbance values (at $405 \mathrm{~nm}$ ) greater than three times the absorbance of the healthy controls were considered positive.

Total RNA extraction. Total RNA was extracted from healthy and infected tissue (100 mg) using the QIAGEN RNeasy Total RNA kit (QIAGEN, Chatsworth, CA). The 
extraction procedure used was essentially as described by the supplier except for the following. The tissue was ground in RiboLyser tubes using the HYBAID RiboLyser Cell Disrupter (InterScience Inc., Markham, Ontario, Canada). QIAGEN's RLT buffer (650 or $500 \mu \mathrm{l}$ ) was added to each tube, to which was added $100 \mathrm{mg}$ of woody or herbaceous tissue, respectively; the sample was triturated using the RiboLyser Cell Disrupter. The tubes were centrifuged at $5,000 \times g$ for $5 \mathrm{~min}$, the supernatant collected and added to QIAGEN's QIAShredder spin columns, and the procedure completed as described by the kit's supplier (QIAGEN).

RT-PCR. Approximately $4 \mu \mathrm{g}$ of total RNA in $5 \mu$ l of diethylpyrocarbonatetreated double-distilled (depc) $\mathrm{H}_{2} \mathrm{O}$ was combined with $2 \mu \mathrm{l}$ of antisense P1 primer (approximately $20 \mathrm{pmol}$ ) and incubated at $75^{\circ} \mathrm{C}$ for $5 \mathrm{~min}$. RT was carried out in a $20-\mu \mathrm{l}$ volume by adding $13 \mu \mathrm{l}$ of RT mix. The RT mix consisted of $4 \mu$ lof $5 \times$ First Strand buffer (Gibco BRL, Life Technologies, Burlington, Ontario), $2 \mu \mathrm{l}$ of $0.1 \mathrm{M}$ dithiothreitol (DTT), $1 \mu \mathrm{l}$ of $10 \mathrm{mM}$ dNTP Mix, $0.5 \mu \mathrm{l}$ of RNase Block (Stratagene, La Jolla, CA), and $1 \mu$ of SUPERSCRIPT II (Gibco BRL), and was adjusted up to a final volume of $13 \mu \mathrm{l}$ with depc $\mathrm{H}_{2} \mathrm{O}$. The PCR reaction mix consisted of $2 \mu$ of 10 mM dNTP mix, $3 \mu \mathrm{l}$ of $50 \mathrm{mM} \mathrm{MgCl} 2,1 \mu \mathrm{l}$ of sense primer (P2, $12 \mathrm{pmol}), 1 \mu \mathrm{l}$ of antisense primer (P1, $12 \mathrm{pmol}), 1 \mu \mathrm{l}$ of Taq DNA polymerase (Gibco BRL), $1 \mu$ of Taq Extender PCR Additive (Stratagene), and $10 \mu \mathrm{l}$ of $10 \times$ Taq Extender buffer, adjusted to a final volume of $80 \mu \mathrm{l}$ with depc $\mathrm{H}_{2} \mathrm{O}$. The final volume of each reaction was 100 $\mu \mathrm{l}(20+80)$. The final reaction $(10 \mu \mathrm{l})$ was assessed by agarose gel electrophoresis.

Heminested PCR. Heminested PCR using D- and M-specific sense primers combined with the P1 PPV antisense primer were used for strain typing (18).

RFLP analysis. Three different regions of the virus genome were targeted for strain typing using RFLP analysis of RT-PCRamplified fragments. These included (i) the coat protein $(\mathrm{CP})$ coding region (23), (ii) the replicase $(\mathrm{NIb})$ gene region (8), and (iii) the $\mathrm{P} 3-6 \mathrm{~K}_{1}$ genomic region (7).
When amplification of 3174-01 was successful, agarose gel-purified cDNA was quantified by spectrophotometry, then subjected to restriction endonuclease digestion.

Strain-specific RT-PCR. RT-PCR specific for strain $\mathrm{C}$ isolates of PPV was carried out (15). Both sets of primers were assessed; HsoC-1/CsoC-1 amplifies a 259- bp fragment, and $\mathrm{HsoC}-2 / \mathrm{CsoC}-2$ amplifies a 193-bp fragment with sour cherry isolates of PPV.

The integrated RT-PCR/nested PCR technique (20) also was used in attempting to determine the PPV strain to which isolate 3174-01 belongs.

Western blot analysis. Leaf tissue from healthy and infected plants was triturated

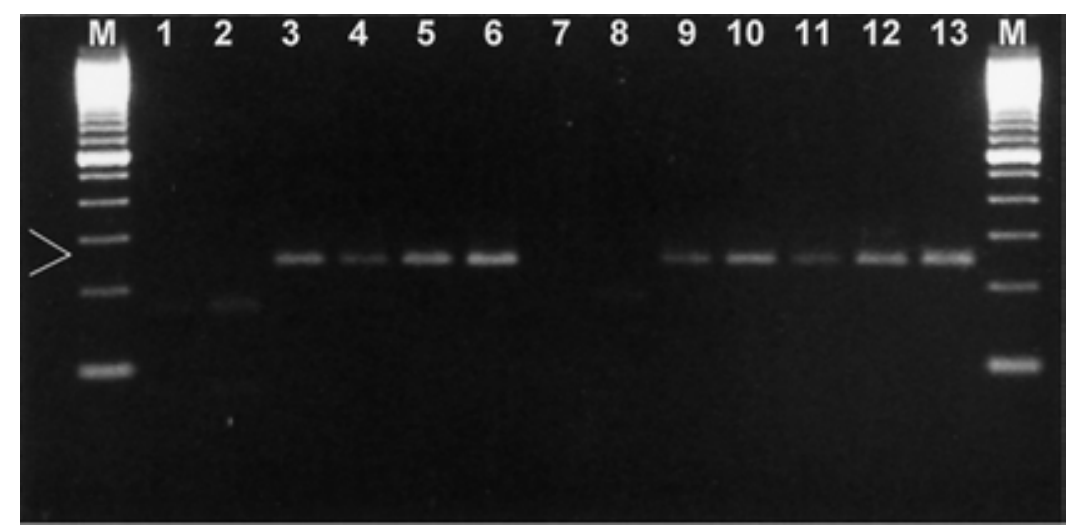

Fig. 1. Reverse-transcription polymerase chain reaction and restriction fragment length polymorphism showing amplification but no digestion of the Plum pox virus 3174-01-associated 243-bp fragment (23). The fragments were treated with the restriction endonucleases AluI (lanes 1-6) and $R s a \mathrm{I}$ (lanes 8-13); lane 7 is blank. Lane M, 100-bp DNA ladder; lanes 1 and 8, Q2185-02 (D); lanes 2 and 9, Q1902-01 (M); lanes 3-6 and 10-13, 3174-01 in plum. The arrow indicates the position of the 243-bp fragment.

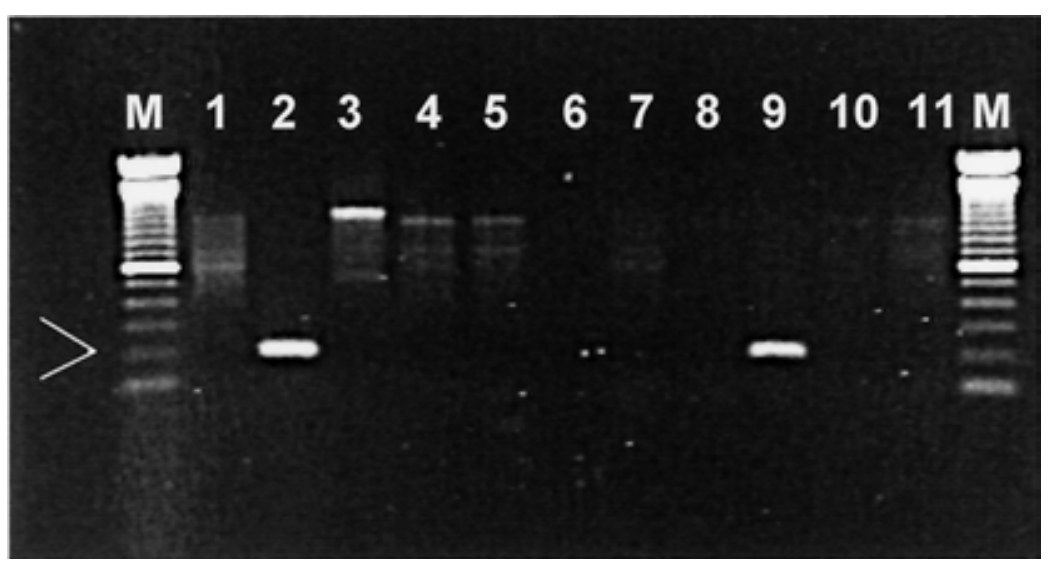

Fig. 2. Heminested polymerase chain reaction using D-specific (lanes 1-5) and M-specific primers (lanes 7-11) for the amplification of a 193-bp fragment (18). Lane 6 is blank. Lane M, 100-bp DNA ladder; lanes 1 and 7, healthy GF305; lanes 2 and 8, Q2185-02 (D); lanes 3 and 9, Q1902-01 (M); lanes 4, 5, 10, and 11,3174-01 in plum. The arrow indicates the position of the 193-bp fragment.

Table 1. Average absorbance values $(n=11,405 \mathrm{~nm}$ ) of triple-antibody sandwich enzyme-linked immunosorbent assay for isolate $3174-01$ and control samples using the universal Plum pox virus (PPV)-specific monoclonal antibody (MAb) 5B, and the D-, M-, EA-, and C-specific MAbs ${ }^{\mathrm{a}}$

\begin{tabular}{|c|c|c|c|c|c|}
\hline \multirow[b]{2}{*}{ Samples } & \multicolumn{5}{|c|}{ Detecting antibody $^{b}$} \\
\hline & $5 B$ & 4D & $\mathbf{A L}$ & EA24 & $\mathbf{A C}$ \\
\hline 3174-01 Plum & 0.174 & 0.024 & 0.018 & 0.032 & 0.027 \\
\hline 3174-01 Nicotiana benthamiana & 0.483 & 0.033 & 0.024 & 0.024 & 0.139 \\
\hline PPV-D N. benthamiana & 1.09 & 0.301 & 0.020 & 0.023 & 0.102 \\
\hline PPV-M N. benthamiana & 0.808 & 0.032 & 0.240 & 0.019 & 0.031 \\
\hline PPV-EA $N$. benthamiana & 0.623 & 0.027 & 0.021 & 0.560 & 0.142 \\
\hline PPV-C N. benthamiana & 0.702 & 0.027 & 0.021 & 0.022 & 1.62 \\
\hline Healthy $N$. benthamiana & 0.044 & 0.026 & 0.020 & 0.026 & 0.200 \\
\hline Healthy Shiro Plum & 0.044 & 0.031 & 0.022 & 0.021 & 0.034 \\
\hline
\end{tabular}

a Readings were taken $1 \mathrm{~h}$ after addition of the substrate.

b 4D = D-specific MAb, AL = M-specific MAb, EA24 = El Amar-specific MAb, and AC = C-specific MAb. Positive values ( $>3 \times$ absorbance of healthy control) are in bold. 
in $0.01 \mathrm{M}$ potassium phosphate buffer $(\mathrm{pH}$ 7.0) containing $0.02 \mathrm{M}$ diethyldidithiocarbamic acid, sodium salt, $0.04 \mathrm{M}$ sodium thioglycolate, and $0.5 \%$ nicotine. Proteins were resolved under denaturing conditions by sodium dodecyl sulphate-polyacrylamide gel electrophoresis (10), and electroblotted using a Semi-Dry Transfer Unit (Bio-Rad, Mississauga, Ontario, Canada) onto nitrocellulose membranes $(0.45-\mu \mathrm{m}$ pore size; Schleicher \& Schuell, Keene, $\mathrm{NH}$ ). Prestained markers (Bio-Rad) were used to assess transfer of the proteins from the gel to the membrane. Blots were screened with the MAbs described above. All MAbs were used at a 1:1000 dilution. Goat anti-mouse alkaline phosphatase conjugate (1:2000; Bio-Rad) was used as the

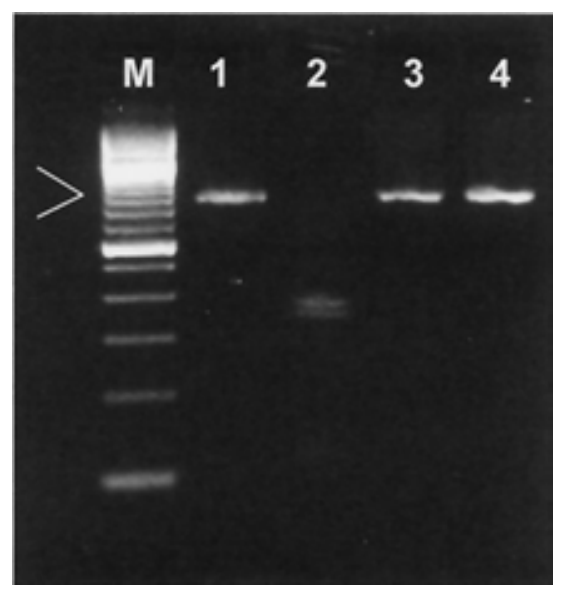

Fig. 3. Reverse-transcription polymerase chain reaction and restriction fragment length polymorphism of the Plum pox virus $\mathrm{P} 3-6 \mathrm{~K}_{1}$ 836-bp fragment (7). The fragments were treated with the restriction endonuclease AsnI. Lane M, 100-bp DNA ladder; lane 1, Q2185-02 (D); lane 2, Q1902-01 (M); lanes 3 and 4, 3174-01 in Nicotiana benthamiana. The arrow indicates the position of the 836-bp fragment.

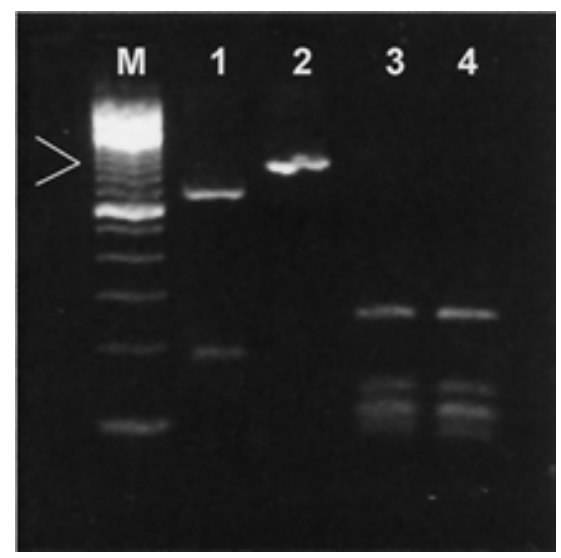

Fig. 4. Reverse-transcription polymerase chain reaction and restriction fragment length polymorphism of the Plum pox virus $\mathrm{P} 3-6 \mathrm{~K}_{1}$ 836-bp fragment (7). The fragments were treated with the restriction endonuclease DdeI. Lane M, 100-bp DNA ladder; lane 1, Q2185-02 (D); lane 2, Q1902-01 (M); lanes 3 and 4, 3174-01 in Nicotiana benthamiana. The arrow indicates the position of the 836-bp fragment. secondary antibody, with NBT-BCIP substrates used as recommended by the supplier (Bio-Rad). The blocking buffer consisted of $0.05 \mathrm{M}$ Tris, $0.15 \mathrm{M}$ sodium chloride, $\mathrm{pH} 7.4$, containing either $1 \%$ bovine serum albumin or $2 \%$ skimmed milk powder to minimize spurious crossreactions (24).

Cloning of complementary DNA. Complementary (c)DNA was generated by RT-PCR using Taq DNA polymerase as described above. Amplified fragments were identified and isolated by agarose gel electrophoresis with ethidium bromide staining. The appropriate bands were excised and purified using QIAGEN's MiniElute Gel Extraction kit (catalog \#28604; QIAGEN Inc., Mississauga, Ontario, Canada). Gel-purified PCR products were ligated into the $\mathrm{pCR}^{(\mathrm{R})} 2.1 \mathrm{TOPO}$ Vector and cloned using the TOPO TA Cloning Kit, as directed by the supplier (Invitrogen, Carlsbad, CA).

Sequencing and sequence analysis. Sequencing was carried out as described by James and Upton (9). Nucleotide sequence data were compiled and analyzed using the
Staden Program package (6) and database searches were performed with BLAST (blastn) programs at the National Centre for Biotechnology Information (NCBI, National Institutes of Health).

\section{RESULTS}

TAS-ELISA. Isolate 3174-01 was detected by the universal PPV MAb 5B in both plum and Nicotiana benthamiana (Table 1). None of the strain-specific MAbs reacted with 3174-01. They did, however, react with the appropriate positive control virus (Table 1).

RT-PCR analysis. A 243-bp fragment was amplified for all samples of 3174-01 tested, using the P1 and P2 primers (Fig. 1). A fragment of similar size was observed for the positive PPV controls, including isolates of D, M, EA, and C (Fig. 1; lane 9 shows the $\mathrm{M}$ fragment). No amplification was observed with any of the healthy controls included in this study.

Heminested PCR. The D-specific primer detected isolate Q2185-02 (Fig. 2, lane 2) and did not detect Q1902-01 (Fig. 2, lane 3) or isolate 3174-01 (Fig. 2, lanes

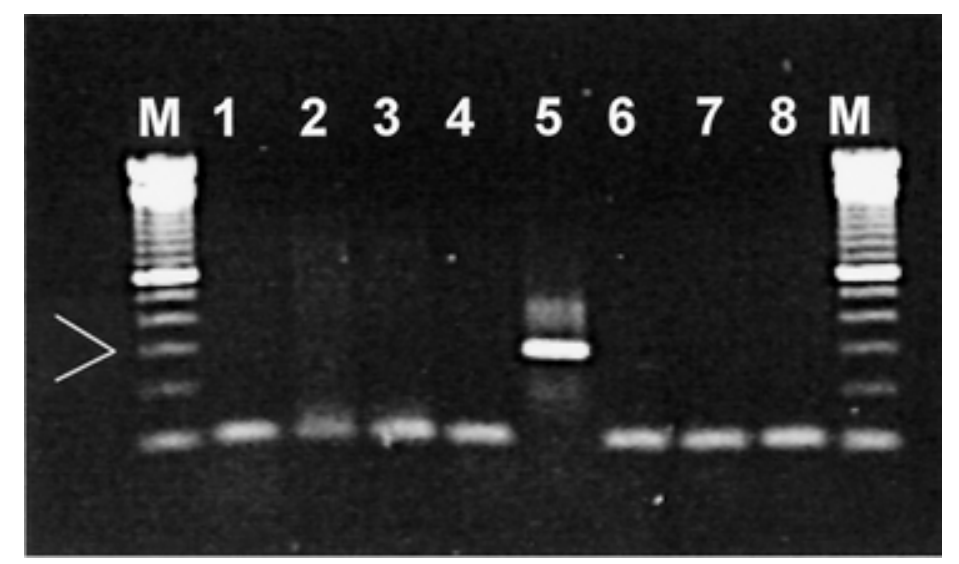

Fig. 5. Reverse-transcription polymerase chain reaction using the Plum pox virus C (PPV-C)-specific primers HsoC-1/CsoC-1 to amplify a PPV-C specific fragment of 259 bp (15). Lane M, 100-bp DNA ladder; lane 1, healthy GF305; lane 2, Q2185-02 (D); lane 3, Q1902-01 (M); lane 4, 20-4-1 (D); lane 5, PPV-C (sweet cherry isolate); lanes 6-8, isolate 3174-01. The arrow indicates the position of a band estimated at $300 \mathrm{bp}$.

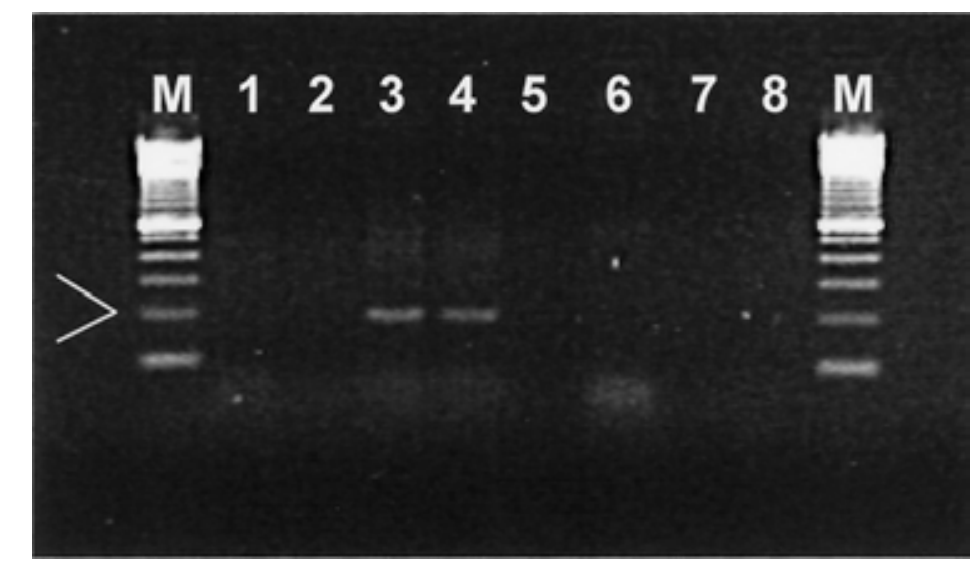

Fig. 6. Reverse-transcription polymerase chain reaction using the Plum pox virus (PPV-C)-specific primers HsoC-2/CsoC-2 to amplify a PPV-C specific fragment of 193 bp (15). Lane M, 100-bp DNA ladder; lane 1, healthy GF305; lane 2, 20-4-1 (D); lanes 3 and 4, PPV-C (sweet cherry isolate); lane 5, 20-4-1 (D); lanes 6-8, isolate 3174-01. The arrow indicates the position of the 193 bp fragment. 
4 and 5). The M-specific primer detected isolate Q1902-01 (Fig. 2, lane 9), but did not detect isolate Q2185-02 or any samples of 3174-01 (Fig. 2, lanes 8, 10, and 11, respectively). All negative controls were negative (Fig. 2, lanes 1 and 7).

RFLP analysis. $C P$ coding region. The amplified 243-bp fragment was treated with the enzymes $A l u \mathrm{I}$ and RsaI. When treated with the restriction endonuclease AluI, the PPV-associated 243-bp products of Q2185-02 (D) and Q1902-01 (M) were digested into fragments of approximately 95 and 148 bp (Fig. 1, lanes 1 and 2, respectively). The 3174-01-associated 243bp fragments (Fig. 1, lanes 3 to 6) were unaffected by the enzyme $A l u \mathrm{I}$. Treatment with the endonuclease $R s a$ I resulted in the digestion of the PCR product of isolate Q2185-02 (D strain; Fig. 1, lane 8). Isolate Q1902-01 (M strain) and all samples of 3174-01 were unaffected by the enzyme RsaI (Fig. 1, lanes 9 and 10 to 13, respectively).

NIb region. The 1,040-bp fragment required for digestion with the enzymes $D d e \mathrm{I}, R s a \mathrm{I}$, and TaqI was not amplified when samples of 3174-01 were treated with the recommended primers. Isolates of strain $\mathrm{D}$ and $\mathrm{M}$ included as controls gave the expected fragment and RFLP profile (data not shown).

P3-6K region. The 836-bp fragment required for digestion with the enzymes AsnI, DdeI, and EcoRI was amplified when samples of 3174-01 were treated with the recommended primers. Isolates of strain $\mathrm{D}$ and $M$ included as controls gave the expected fragment and RFLP profile (Figs. 3 and 4). The 3174-01-derived fragment lacked an AsnI restriction site and contained a single EcoRI restriction site, which was similar to the pattern observed for Q2185-02 (D). The results after treatment with AsnI are shown in Figure 3. Treatment of the 3174-01-derived fragment with the enzyme DdeI produced a restriction profile different from that of Q2185-02 (D) and Q1902-01 (M) (Fig. 4). Four fragments were observed after DdeI treatment of the 3174-01 product (Fig. 4, lanes 3 and 4), indicating the presence of at least three DdeI restriction sites. Q2185-02 (D) and Q1902-01 (M) had one

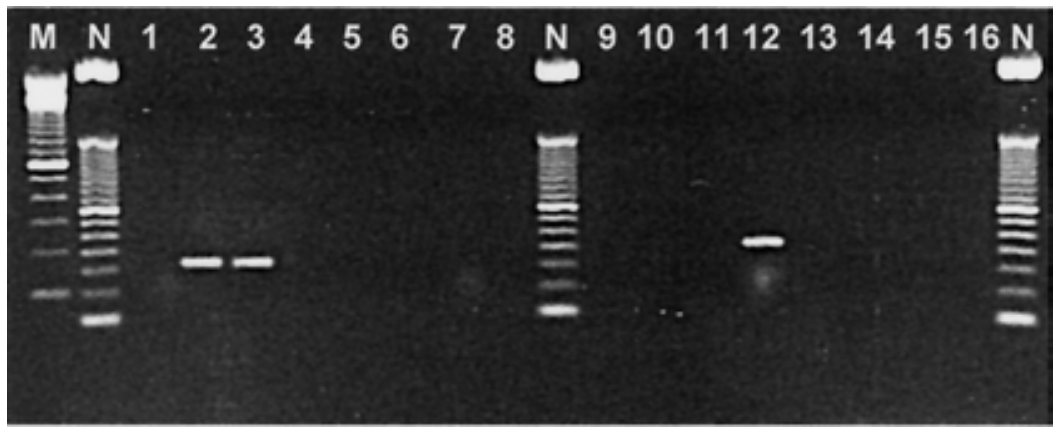

Fig. 7. Strain typing Plum pox virus (PPV) isolate 3174-01 using integrated reverse-transcriptionpolymerase chain reaction (PCR)/nested PCR (20). The D-specific primers M1-5' and M5-3' (lanes 1-8) and the M-specific primers M6-5' and M7-3' (lanes 9-16) were used. Lanes M, and N, 100- and 50-bp DNA ladder, respectively; lanes 1 and 9, healthy GF305; lanes 2 and 10, 20-13-1 (D); lanes 3 and 11, Q2185-02 (D); lanes 4 and 12, Q1902-01 (M); lanes 5 and 13, PPV-C (sweet cherry isolate); lanes 6-8 and 14-16, isolate 3174-01. The 159-bp D-specific fragment is present in lanes 2 and 3. The 207-bp M-specific fragment is present in lane 12.

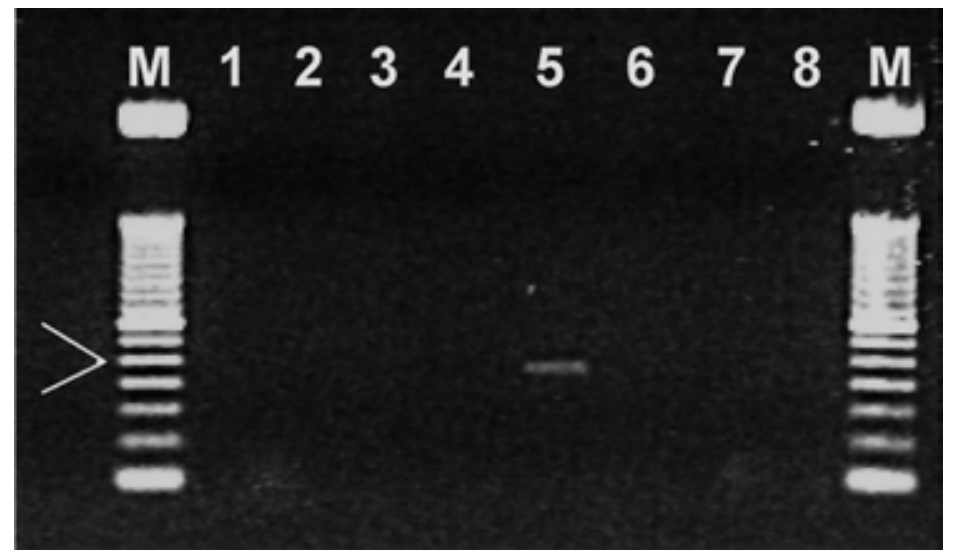

Fig. 8. Strain typing Plum pox virus (PPV) isolate 3174-01 by integrated reverse-transcription polymerase chain reaction (PCR)/nested PCR using the C-specific primers M10-5' and M11-3' (20). Lane M, 50-bp DNA ladder; lane 1, healthy GF305; lane 2, 20-13-1 (D); lane 3, Q2185-02 (D); lane 4, Q1902-01 (M); lane 5, PPV-C (sweet cherry isolate); and lanes 6-8, isolate 3174-01. The arrow indicates the position of the 224-bp C-specific fragment. and no DdeI sites, respectively (Fig. 4, lanes 1 and 2).

Strain-specific RT-PCR. The only sample for which amplification was observed when RT-PCR was carried out with the HsoC-1/CsoC-1 primer pair was the sample of PPV-C (Fig. 5, lane 5). A fragment of approximately $300 \mathrm{bp}$ in size was observed. No amplification was observed for any of the other samples included. When the HsoC-2/CsoC-2 primer pair was used in RT-PCR, amplification of a 193-bp fragment was observed only for the two samples of PPV-C included in the study (Fig. 6, lanes 3 and 4). No amplification was observed for any of the other samples, including 3174-01.

Analysis using the integrated RT$\mathrm{PCR} /$ nested PCR technique produced the expected results with all the positive controls included in this study (Figs. 7 and 8). No amplification was observed for any of the 3174-01 samples with any of the strainspecific primers, including the $\mathrm{C}$-specific primers M10-5' and M11-3'. These primers amplified the expected 224-bp fragment with the PPV-C control (Fig. 8, lane 5). The EA-specific primers (M8-5' and M9$3^{\prime}$ ) amplified a 167-bp fragment with the EA-positive control, but were negative for all other samples, including samples of 3174-01 (data not shown).

Western blot analysis. PPV isolate 3174-01 and all positive controls were detected with the universal PPV MAb 5B (Table 2). The rate of migration of the coat protein subunit of 3174-01 was similar to that of isolate Q2185-02 (D), with an approximate molecular mass of $32 \mathrm{kDa}$. The D-, M-, EA-, and C-specific MAbs did not react with 3174-01 in Western blot analysis (Table 2). The specific MAbs reacted with their appropriate positive controls and no cross-reactions were observed (Table 2).

Sequence analysis. Two clones containing the 243-bp fragment of isolate 317401 , amplified by using the P1 and P2 primers as described above, were sequenced and the nucleotide sequence analyzed. These clones were derived from samples amplified separately. There were 13 nucleotide changes $(5.3 \%)$ between the two sequences. The enzymes RsaI and $A l u \mathrm{I}$ recognize the restriction sites GTAC and AGCT, respectively. In isolate 3174-01, these sequences are replaced by GTAA/GTGA and GGCA, respectively (Fig. 9), which explains the failure of any digestion with these enzymes. When aligned and compared with sequences of PPV-C (X97398), PPV-M (M92280), PPVEA (X56258), PPV-D (X16415), and PPV$\mathrm{Fa}$ (a Canadian isolate of PPV strain D), identities of 95 to 99,92 to $94,91,94$, and $94 \%$, respectively, were observed.

\section{DISCUSSION}

Isolate 3174-01 was detected with the PPV-specific MAb 5B in both TAS-ELISA and Western blot assays. Also, the virus 
was detected by RT-PCR using the PPVspecific primers $\mathrm{P} 1$ and $\mathrm{P} 2$ (23), indicating that it is, indeed, an isolate of PPV.

Isolate 3174-01 was not detected with oligonucleotide primers known to be specific for the D or M strain of PPV (18). The 243-bp fragment, amplified using the $\mathrm{P} 1$ and $\mathrm{P} 2$ primers, can be utilized in RFLP analysis for reliably distinguishing different strains of PPV (23). Two restriction sites (RsaI and $A l u \mathrm{I})$ are associated with this fragment. Members of strain D possess both restriction sites, members of $\mathrm{M}$ and EA possess the $A l u \mathrm{I}$ site but lack the RsaI site, and members of strain C lack both restriction sites. The 3174-01-associated 243-bp fragment lacks both restriction sites. This suggested the possibility that 3174-01 was a member of PPV strain C. The primer pairs HsoC-1/CsoC-1 and HsoC-2/CsoC-2 (15) have been used for reliable detection of sour cherry and sweet cherry isolates of PPV strain C. Neither of these primer pairs could detect isolate 3174-01. The primer pair Hsoc-1/CsoC-1 amplifies a 259-bp product with sour cherry isolates of PPV-C (15). In this study, a fragment of approximately $300 \mathrm{bp}$ was amplified with a sweet cherry isolate of PPV-C; therefore, it is possible that this primer pair may be useful in distinguishing sweet and sour cherry isolates of PPV-C.

RFLP analysis in the P3- $6 \mathrm{~K}_{1}$ region of the PPV genome has been described as a reliable region for confirming the identity of $\mathrm{D}$ and $\mathrm{M}$ strains (7). Restriction analysis of the 3174-01-associated 836-bp fragment indicated the presence of a single EcoRI restriction site and the absence of any AsnI site, which is similar to strain D. Analysis with the enzyme DdeI revealed the presence of at least three DdeI sites,

Table 2. Western blot analysis using the universal Plum pox virus (PPV)-specific monoclonal antibody (MAb) 5B, and D-, M-, EA-, and C-specific MAbs for the detection of PPV isolate 3174-01

\begin{tabular}{lccccc}
\hline & \multicolumn{5}{c}{ MAb $^{\mathbf{a}}$} \\
\cline { 2 - 6 } Isolate $^{\mathbf{b}}$ & $\mathbf{5 B}$ & 4D & AL & EA24 & AC \\
\hline $3174-01$ & + & - & - & - & - \\
Q2185-02 (D) & + & + & - & - & - \\
Q1902-01 (M) & + & - & + & - & - \\
$20-4-1$ (D) & + & + & - & - & - \\
PPV-C & + & - & - & - & + \\
PPV-EA & + & - & - & + & - \\
Healthy Nicotiana benthamiana & - & - & - & - & - \\
\hline
\end{tabular}

${ }^{a}$ Detection: $+=$ positive and $-=$ negative .

${ }^{\mathrm{b}} \mathrm{D}=\mathrm{PPV}$ strain $\mathrm{D}$ and $\mathrm{M}=\mathrm{PPV}$ strain $\mathrm{M}$.

compared with one and none for strains D and $\mathrm{M}$, respectively. This region has not been used to identify strain C or EA (7).

An integrated RT-PCR/nested PCR technique has been described (20) that reliably distinguishes all four strains of PPV, including isolates of PPV-C. All recommended combinations were assessed in this study but all were negative for 3174-01, including the $\mathrm{C}$-specific primers. Western blot assays were attempted and these included analyses with D-, M-, EA-, and C-specific MAbs. All were negative for 3174-01. Only the universal monoclonal antibody $5 \mathrm{~B}$ reacted with $3174-01$, and the molecular mass of 3174-01 was estimated to be approximately $32 \mathrm{kDa}$, similar to that of the member of the D strain included in the study. In all cases where the strainspecific MAbs were used, reactions were observed with the corresponding positive controls but not with isolate 3174-01.

It is interesting that the changes to $3174-$ 01 in the region of the $A l u \mathrm{I}$ and $R s a \mathrm{I}$ restriction sites in the $\mathrm{C}$-terminus of the $\mathrm{CP}$ coding region are similar to that observed in association with members of PPV-C. Analysis of the cDNA of 3174-01 corresponding to the $\mathrm{C}$-terminal region of the coding region revealed either GTAA or GTGA at the position of the RsaI restriction site. This, along with other nucleotide differences among cDNA clones, provides evidence of a mixed population, with all members lacking the restriction sites. Mixed populations of PPV in a single tree

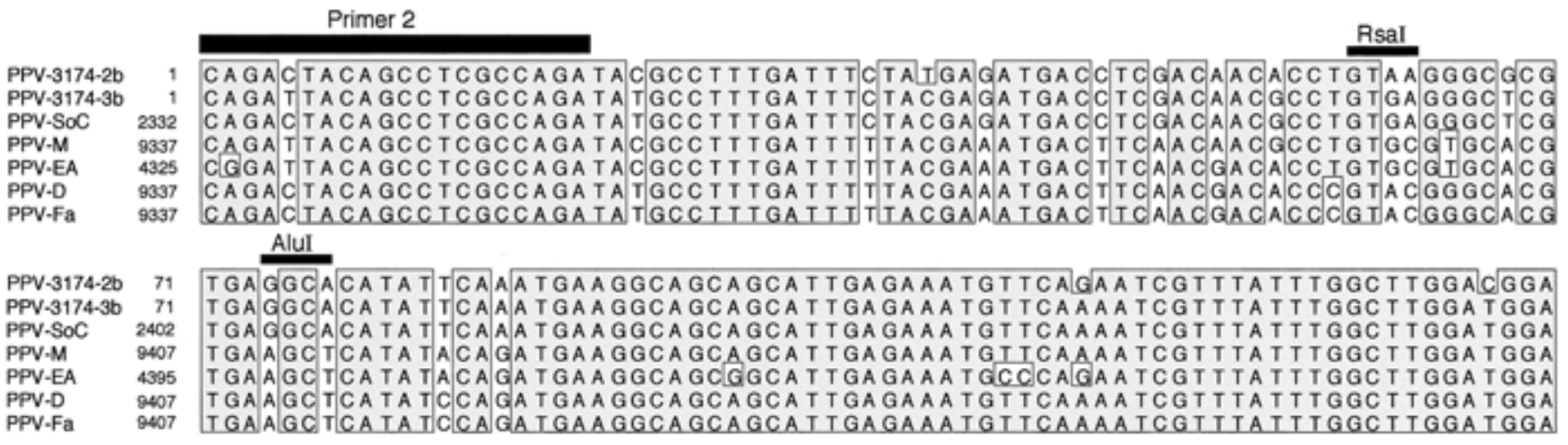

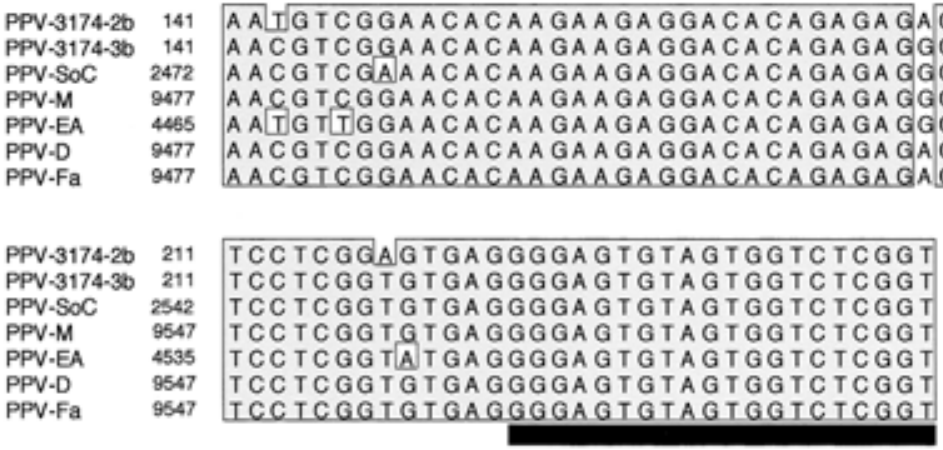

\section{Primer 1}

Fig. 9. Multiple alignment of the nucleotide sequence of the 243-bp amplified fragment in the C-terminal region of the coat protein coding region of Plum pox virus (PPV) showing the RsaI and AluI endonuclease restriction sites (23). Samples (with accession number where appropriate) include PPV-3174-2b, PPV-3174-3b, PPV-C (X97398), PPV-M (M92280), PPV-EA (X56258), PPV-D (X16415), and PPV-Fa (Canadian D isolate). 
are not uncommon (8). The identity in this 243-bp region was highest between 317401 and PPV-C (95 to 99\%). It is possible that 3174-01 was derived from PPV-C, or is more closely related to PPV-C than to any other PPV strain. PPV-C and 3174-01 lack the $R s a \mathrm{I}$ and $A l u \mathrm{I}$ restriction sites. This does not mean that they must, therefore, belong to the same strain. PPV-EA and PPV-M are different strains that are similar in terms of the restriction profile in this region. They both lack the restriction site RsaI.

It would appear that 3174-01 is not a member of any of the previously described strains of PPV. This conclusion is based on (i) the absence of both restriction sites AluI and RsaI in the C-terminal region of the coat protein coding region of 3174-01; (ii) failure of amplification with two sets of Cspecific primers; (iii) an inability to detect this isolate with any of the strain-specific primer combinations described for integrated RT-PCR/nested PCR detection (20), including $\mathrm{C}$-specific primers; (iv) failure of amplification using primers that target the replicase gene region (8) for RFLP analysis; and (v) a lack of recognition by D-, M-, EA-, and C-specific MAbs, All studies were replicated at least twice; in some cases, four replicates were used. This provides a high level of confidence in the results obtained.

This isolate of PPV was detected in plum ( $P$. domestica) from a homeowner's property and appears to represent an isolated find, with no other positive plants detected to date in the immediate vicinity. The homeowner indicated that the plant germ plasm originally was introduced into Canada from Eastern Europe as "seed" and that the trees tested were approximately 10 years old. There are two important issues worth noting: (i) if the original plant material was infected with this virus and was introduced as seed, then there is circumstantial evidence for seed transmission of this isolate of PPV, although this must be confirmed by experimental analysis; and (ii) the activities of homeowners in moving plant germ plasm across borders without proper certification poses a serious threat to agricultural and horticultural industries.

Studies are underway to completely sequence this PPV isolate and assess its host range, including budding or grafting infected tissue onto cherry, to further characterize and obtain data that may facilitate accurate classification of this unusual isolate of PPV. Vernalization and germination of seed collected from the infected plum trees are underway. The seedlings will be tested for the presence of PPV.

\section{ACKNOWLEDGMENTS}

We thank A. Walter for technical assistance; M. Cambra and A. Myrta for samples of strain-specific monoclonal antibodies; F. Dosba, W. Jelkmann, and A. Myrta for kindly providing samples of known isolates of PPV-M, PPV-D, and PPV-C and EA, respectively; and the St. Catharines survey crew of CFIA for providing samples of 317401 and other isolates of PPV for analysis.

\section{LITERATURE CITED}

1. Boscia, D., Zeramdini, H., Cambra, M., Potere, O., Gorris, M. T., Myrta, A., Di Terlizzi, B., and Savino, V. 1997. Production and characterization of a monoclonal antibody specific to the $\mathrm{M}$ serotype of plum pox potyvirus. Eur. J. Plant Pathol. 103:477-480.

2. Cambra, M., Asenio, M., Gorris, M. T., Perez, E., Camarasa, E., Garcia, J. A., Moya, J. J., Lopez-Abella, D., Vela, C., and Sanz, A. 1994. Detection of plum pox potyvirus using monoclonal antibodies to structural and nonstructural proteins. EPPO Bull. 24:569-577.

3. Candresse, T., Macquaire, G., Lanneau, M., Bousalem, M., Wetzel, T., Quiot-Douine, L., Quiot, J. B., and Dunez, J. 1994. Detection of plum pox potyvirus and analysis of molecular variability using immunocapture-PCR. EPPO Bull. 24:585-594.

4. Clark, M. F., and Adams, A. N. 1977. Characteristics of the microplate method of enzymelinked immunosorbent assay for the detection of plant viruses. J. Gen. Virol. 34:475-483.

5. Crescenzi, A., d'Aquino, L., Comes, S., Nuzzaci, M., Boscia, D., Piazolla, P., and Hadidi, A. 1997. Characterization of the sweet cherry isolate of plum pox potyvirus. Plant Dis. 81:711-714.

6. Dear, S., and Staden, R. 1991. A sequence assembly and editing program for efficient management of large projects. Nucleic Acids Res. 19:3907-3911.

7. Glasa, M., Marie-Jeanne, V., Moury, B., Kúdela, O., and Quiot, J.-B. 2002. Molecular variability of the $\mathrm{P} 3-6 \mathrm{~K}_{1}$ genomic region among geographically and biologically distinct isolates of Plum pox virus. Arch. Virol. $147: 563-575$

8. Hammond, J., Pühringer, H., da Câmara Machado, A., and Laimer da Câmara Machado, M. 1998. A broad spectrum PCR assay combined with RFLP analysis for detection and differentiation of plum pox virus isolates. Acta Hortic. 472:483-490.

9. James, D., and Upton, C. 2001. Molecular characterization and comparison of the 3 '-terminal region of two Canadian isolates of plum pox virus. (Abstr.) Phytopathology 91:S43.

10. Laemmli, U. K. 1970. Cleavage of structural proteins during the assembly of the head of bacteriophage T4. Nature (Lond.) 227:680-685.
11. Lain, S., Riechmann, J. L., and Garcia, J. A. 1989. The complete nucleotide sequence of plum pox potyvirus RNA. Virus Res. 13:157172.

12. Levy, L., Damsteegt, V., Mavrodieva, V., Goley, E., Welliver, R., and Luster, D. 2000. Partial characterization of the Pennsylvania strain of plum pox virus (PPV-PA). (Abstr.) Phytopathology 90:S46.

13. Maiss, E., Timpe, U., Brisske, E., Jelkmann, W., Casper, R., Himmler, G., Mattanovich, D., and Katinger, H. W. D. 1989. The complete nucleotide sequence of plum pox virus RNA. J. Gen. Virol. 70:513-524.

14. Myrta, A., Potere, O., Crescenzi, A., Nuzzaci, M., and Boscia, D. 2000. Properties of two monoclonal antibodies specific to the cherry strain of plum pox virus. J. Plant Pathol. 82:95-101.

15. Nemchinov, L., Crescenzi, A., Hadidi, A. Piazzolla, P., and Verderevskaya, T. 1998. Present status of the new cherry subgroup of plum pox virus (PPV-C). Pages 629-638 in: Plant Virus Disease Control. A. Hadidi, R. K. Khetarpal, and H. Koganezawa, eds. American Phytopathological Society Press, St. Paul, MN.

16. Nemchinov, L., and Hadidi, A. 1996. Characterization of the sour cherry strain of plum pox virus. Phytopathology 86:575-580.

17. Nemeth, M. 1986. Plum pox (sharka). Pages 463-479 in: Virus, Mycoplasma and Rickettsia Diseases of Fruit Trees. Akademiai Kiado, Budapest.

18. Olmos, A., Cambra, M., Dasi, M. A., Candresse, T., Esteban, O., Gorris, M. T., and Asenio, M. 1997. Simultaneous detection and typing of plum pox potyvirus (PPV) isolates by Heminested- PCR and PCR-ELISA. J. Virol. Methods 68:127-137.

19. Poggi Pollini C., Giunchedi, L., and Bissani, R. 1997. Specific detection of D- and M-isolates of plum pox virus by immunoenzymatic determination of PCR products. J. Virol. Methods 67:127- 133.

20. Szemes, M., Kálman, M., Myrta, A., Boscia, D., Németh, M., Kölber, M., and Dorgai, L. 2001. Integrated RT-PCR/nested PCR diagnosis for differentiating between subgroups of plum pox virus. J. Virol. Methods 92:165175.

21. Teycheney, P. Y., Tavert, G., Delbos, R., Ravelonandro, M., and Dunez, J. 1989. The complete nucleotide sequence of plum pox virus RNA (strain D). Nucleic Acids Res. 17:10115-10116.

22. Thompson, D., McCann, M., MacLeod, M., Lye, D., Green, M., and James, D. 2001. First report of plum pox potyvirus in Canada. Plant Dis. 85:97.

23. Wetzel, T., Candresse, T., Ravelonandro, M., and Dunez, J. 1991. A polymerase chain reaction assay adapted to plum pox potyvirus detection. J. Virol. Methods 33:355-365.

24. Zimmerman, D., and Van Regenmortel, M. H. 1989. Spurious cross-reactions between plant viruses and monoclonal antibodies can be overcome by saturating ELISA plates with milk proteins. Arch. Virol. 106:15-22. 